Nova Southeastern University

Florida

NSUWorks

CAHSS Faculty Articles

Faculty Scholarship

8-2-2013

\title{
Resilience and Syndemic Risk Factors among African-American Female Sex Workers
}

\author{
Mance E. Buttram \\ Nova Southeastern University, mance.buttram@nova.edu \\ Hilary L. Surratt \\ Nova Southeastern University, surratt@nova.edu \\ Steven P. Kurtz \\ Nova Southeastern University, steven.kurtz@nova.edu
}

Follow this and additional works at: https://nsuworks.nova.edu/shss_facarticles

Part of the Medicine and Health Sciences Commons, and the Sociology Commons

\section{NSUWorks Citation}

Buttram, M. E., Surratt, H. L., \& Kurtz, S. P. (2013). Resilience and Syndemic Risk Factors among AfricanAmerican Female Sex Workers. Psychology, Health \& Medicine, 19 (4), 442-452. https://doi.org/10.1080/ 13548506.2013.824595

This Article is brought to you for free and open access by the Faculty Scholarship at NSUWorks. It has been accepted for inclusion in CAHSS Faculty Articles by an authorized administrator of NSUWorks. For more information, please contact nsuworks@nova.edu. 


\title{
Resilience and syndemic risk factors among African-American female sex workers
}

\author{
Mance E. Buttram, Hilary L. Surratt \& Steven P. Kurtz
}

To cite this article: Mance E. Buttram, Hilary L. Surratt \& Steven P. Kurtz (2014) Resilience and syndemic risk factors among African-American female sex workers, Psychology, Health \& Medicine, 19:4, 442-452, DOI: 10.1080/13548506.2013.824595

To link to this article: https://doi.org/10.1080/13548506.2013.824595

曲 Published online: 02 Aug 2013.

Submit your article to this journal

Џll Article views: 337

Q View related articles $\longleftarrow$

View Crossmark data $־$

4 Citing articles: 17 View citing articles 


\title{
Resilience and syndemic risk factors among African-American female sex workers
}

\author{
Mance E. Buttram*, Hilary L. Surratt and Steven P. Kurtz \\ Center for Applied Research in Substance Use and Health Disparities, Nova Southeastern \\ University, Miami, FL, USA
}

(Received 13 February 2013; final version received 7 July 2013)

\begin{abstract}
Research on street-based female sex workers documents a multitude of problems faced by these women, such as substance use, HIV risk, mental health problems, victimization, and homelessness. The presence of problems such as these is understood as a syndemic, or co-occurrence of two or more risk factors that act synergistically to create an excess burden of disease. However, the syndemic framework has not previously incorporated the examination of resilience to understand what protective factors enable female sex workers to cope with syndemic risk. Using 562 baseline interviews from street-based African-American female sex workers enrolled in a randomized intervention trial, this study is the first to investigate expressions of resilience among this vulnerable population. Specifically, these analyses examine high levels of resilience, as measured by personal mastery, in order to understand the contributions of syndemic risk factors and protective factors on the expression of resilience. In bivariate logistic regression models, women with high resilience reported significantly higher odds of high school education, greater access to transportation, and more social support, in addition to lower odds of foster care history, homelessness, substance dependence, severe mental distress, victimization, and HIV risk. In the multivariate model, higher odds of high school education and increased social support, in addition to lower odds of mental distress and HIV risk remained associated with high resilience. The findings suggest specific targets for intervention to assist female sex workers in coping with syndemic risk factors and in achieving better health outcomes. These include the prioritizing of education and training opportunities and the enhancement of social support.
\end{abstract}

Keywords: syndemic; resilience; women; sex work; personal mastery

\section{Introduction}

Street-based female sex workers in the US constitute an especially vulnerable population as they are often enmeshed in chronic patterns of substance use, sexual risk, mental distress, victimization, and homelessness (Inciardi \& Surratt, 2001; Kurtz, Surratt, Inciardi, \& Kiley, 2004; Surratt \& Inciardi, 2004; Surratt, Kurtz, Weaver, \& Inciardi, 2005). Victimization at the hands of "dates" (clients or "johns"), boyfriends, and other predators plays a large role in their lives (Kurtz et al., 2004; Surratt, Inciardi, Kurtz, \& Kiley, 2004). At the same time, they are at high risk for loss of social services and social support structures, including family, church (Dalla, 2001; Weiner, 1996), and stable housing (Spittal et al., 2003).

*Corresponding author. Email: mance.buttram@nova.edu 
Research indicates that many of these health and social risk factors, such as violence, substance use, and HIV risk, are co-occurring problems for vulnerable female sex workers (Carlson et al., 2012; Shannon \& Csete, 2010; Shannon et al., 2008). The co-occurrence of two or more risk factors in an individual, interacting synergistically, and contributing to an excess burden of disease, is defined as a syndemic (Millstein, 2002). The syndemic framework calls attention to the synergistic nature of health and social problems and views them as interconnected and the result of structural inequality or lack of resources (Singer \& Snipes, 1992). Among the limited research on female sex workers in the USA, a small number of studies have utilized the syndemic framework to examine the complexities of multiple disparities faced by this population (Romero-Daza, Weeks, \& Singer, 2003, 2005).

Syndemic health and social disparities are also experienced by urban impoverished African-American populations (Baer, Singer, \& Susser, 1997). Overall, AfricanAmericans are more likely to be homeless, incarcerated, and experience higher poverty rates and inequitable access to social, educational, or material resources (Bassuk et al., 1997; DeNavas-Walt, Proctor, \& Smith, 2012; Parrish \& Kent, 2008; Schnittker, Massoglia, \& Uggen, 2011; Susser, Moore, \& Link, 1993). Further, HIV incidence rates among African-American women far exceed those of other American women (Prejean et al., 2011). Thus, the syndemic approach is useful in explaining how health and well-being are related to African-American female sex workers' experiences of inequality and brings to light the complex relationships influencing poor health outcomes (Baer et al., 1997; Romero-Daza et al., 2003).

Recently, syndemic researchers have called for incorporating the study of resilience, or individual strengths and protective factors, into this framework to better understand how vulnerable populations overcome syndemic health disparities (Herrick, Stall, Goldhammer, Egan, \& Mayer, 2013). Though inequality contributes to syndemic health disparities (Baer et al., 1997; Singer, 2009), it does not negate individual agency to seek resources which enhance successful coping (Obrist, Pfeiffer, \& Henley, 2010; Ungar, 2008). Resilience research among female sex workers in the USA is scant, yet international research among this population indicates that better health outcomes are associated with protective factors such as self-efficacy (Ghimire, Smith, van Teijlingen, Dahal, \& Luitel, 2011; Guha et al., 2012).

From this perspective, the current study examines street-based African-American female sex workers in Miami, Florida who report high levels of resilience. Among this population, co-occurring health and social risks, such as substance use, violence, psychological distress, and homelessness, are common (Kurtz, Surratt, Kiley, \& Inciardi, 2005; Surratt \& Inciardi, 2010; Surratt, Kurtz, Chen, \& Mooss, 2011), and the lack of basic necessities such as food, clothing, shelter, and health care is widespread. The illegal and stigmatized nature of sex work in Miami exacerbates these issues, leaving female sex workers largely disconnected from formal help systems due to fear of arrest or other legal repercussions. Within this context, impoverished drug-involved women who lack education, job skills, and access to resources find few economically viable alternatives to sex work (Surratt et al., 2004). These overlapping vulnerabilities are hallmarks of a syndemic, which is tied to adverse health consequences among this population.

Personal mastery was used as an indicator of resilience. As a coping resource, it is associated with improved mental and physical health, reduced risk of mortality, and reduced impact of chronic stress on disease (Roepke \& Grant, 2011). We test the hypothesis that higher resilience will be associated with lower levels of syndemic risk 
factors and elevated levels of protective factors. Though previous examinations of risk factors associated with street-based female sex work in Miami are present in the literature (Inciardi, Surratt, \& Kurtz, 2006; Kurtz et al., 2005; Surratt et al., 2011), this is the first study to investigate expressions of resilience among this population.

\section{Methods}

The data were drawn from a randomized clinical trial designed to test the relative effectiveness of two case management intervention protocols in linking underserved women with health and social services and reducing risk behaviors for HIV. Study enrollment occurred May 2007-June 2010, with 562 eligible clients completing baseline interviews. The target population for this intervention trial was drug-using African-American female sex workers in Miami, Florida. Eligible clients were African-American women ages 18-50 who had (a) traded sex for money or drugs at least three times in the past 30 days; and (b) used cocaine, crack, or heroin three or more times a week in the past 30 days. Participants were recruited using targeted sampling strategies (Waters \& Biernacki, 1989) carried out by a team of professional outreach workers and active sex workers. The outreach staff was indigenous to the target recruitment areas, and several members of the team had prior experience conducting outreach for local community service agencies.

Study recruiters made contact with potential participants in various street locations. Potential participants were asked to contact the field office for telephone screening for eligibility. Those meeting eligibility requirements were scheduled for appointments at the project intervention center, where they were re-screened on arrival. After eligibility was confirmed, informed consent was obtained, followed by a structured face-to-face baseline interview lasting approximately one hour. Study protocols were approved by the University of Delaware (predecessor institution) and Nova Southeastern University Institutional Review Boards.

\section{Data collection and measures}

Interviews were conducted using computer-assisted personal interviews. The Global Appraisal of Individual Needs (GAIN, Vol. 5.4; Dennis, Titus, White, Unsicker, \& Hodgkins, 2002) was the primary component of the standardized baseline assessment. This instrument captured demographic information, physical and mental health status, homelessness, foster care history, violence and victimization, as well as lifetime and 90-day measures of drug use frequency and sexual risk behaviors.

\section{Risk factors}

The GAIN contains clinical measures of mental health based on DSM-IV symptom criteria: Nine items assess past year symptoms of depression and 12 items assess past year symptoms of anxiety disorders (Bohlig \& Dennis, 1996; Dennis, Chan, \& Funk, 2006). This scale is reducible to classifications indicating clinical significance (subclinical, moderate, and severe) (Dennis et al., 2002) and was further dichotomized in the analyses presented here into "severe" and "not severe."

Substance dependence was measured using the TCU Drug Screen II Institute of Behavioral Research (IBR, 2006). Comprised of nine items measuring past year drug 
use severity (e.g. using more or longer than intended, using in unsafe situations), endorsement of three or more items approximates DSM-IV criteria for dependence.

The General Victimization Scale (GVS) is a 15-item measure of types of victimization experienced by the respondent (including lifetime physical, emotional, and sexual victimization), the number of traumagenic factors involved in the victimization (including age at onset, duration, type, and relation of perpetrator) and current worry about victimization (Titus, Dennis, White, Scott, \& Funk, 2003). The four "current worry" items were excluded as they were likely to be universally endorsed. Thus, our GVS scale consists of 11 total items. Higher values indicate increased victimization and/or increased traumatic factors associated with the victimization. For analysis, the measure was dichotomized into "severe" (endorsement of four or more symptoms) and "not severe."

HIV risk was measured by asking clients to report counts of past 90-day vaginal and anal sex times as well as counts of the number of vaginal and anal sex times in which a condom was used. The measure was dichotomized so that HIV risk was defined as one or more unprotected vaginal or anal sex times versus none.

\section{Protective factors}

Healthcare coverage was assessed by asking clients if their medical expenses were covered by any type of insurance, court, or health program. Transportation access was selected as a protective factor because prior research among this population suggested that this resource is lacking and having it would make engaging with health and social services less burdensome (Kurtz et al., 2005). This measure was assessed by asking clients to identify their most common form of transportation. Clients who reported using their personal vehicle or using public transportation were categorized as having "access," while clients reporting walking, biking, or depending on rides from others for the primary mode of transportation were categorized as "no access."

Social support was measured using the 19-item MOS Social Support Survey (Sherbourne \& Stewart, 1991), which includes the domains of emotional/informational support, tangible support, affectionate support, and positive social interaction. Scores were calculated according to the scale's authors' guidelines and were transformed to a 0-100 scale for comparison to published means. Cronbach's alpha for overall social support in this sample was .966 .

\section{Resilience}

Personal mastery (Pearlin \& Schooler, 1978) measures the extent to which an individual believes life events or circumstances are under one's own control. It consists of seven items, answered on a five-point scale, that have good internal reliability (Seeman, 1991) and construct validity (Pearlin, Menaghan, Lieberman, \& Mullan, 1981). For analysis, this scale was used as a proxy for resilience based on the idea that the development of personal mastery is preceded by the cultivation of successful coping or other means of overcoming risk and is a product of these efforts (Younger, 1991). The scale ranged from 11 to 35; higher scores are higher personal mastery. For analysis, the measure was dichotomized at the 66th percentile with high personal mastery defined as the upper $33.3 \%$ versus low personal mastery (lower two-thirds). 


\begin{abstract}
Analysis
Analyses were conducted using IBM SPSS Statistics version 20. Descriptive statistics were calculated for the variables of interest, including demographics, risk factors, protective factors, and personal mastery. Bivariate logistic regression models were constructed to predict high levels of personal mastery by these risk and protective factors. Those measures that exhibited significant associations in the bivariate models were included in a multivariate logistic regression model. Prior to conducting multivariate analysis, collinearity diagnostics were examined and indicated that no variables had problematic VIFs.
\end{abstract}

\title{
Results
}

Table 1 shows selected characteristics of the sample. Mean age was 39. Women in the sample reported being HIV-positive (17.4\%), foster care history $(17.1 \%)$, and past 90-day homelessness $(54.8 \%)$. Reports of syndemic risk factors include severe mental distress (78.8\%), substance dependence (89.1\%), severe victimization (83.3\%), and recent HIV risk $(50.2 \%)$. Protective factors included education ( $\geqslant 12$ years; $48.0 \%$ ), health care coverage $(33.1 \%)$, and transportation access $(68.3 \%)$. On average, clients reported an overall social support score of 55.20 ( $\mathrm{SD}=22.98$; range 19-95).

Results of the bivariate logistic regression models predicting high personal mastery are shown in Table 2. Foster care history $(\mathrm{OR}=.506 ; 95 \% \mathrm{CI}=.301, .851 ; p=.010)$, past 90 -day homelessness $(\mathrm{OR}=.553 ; 95 \% \mathrm{CI}=.361, .846 ; p=.006)$, substance dependence $(\mathrm{OR}=.472 ; 95 \% \mathrm{CI}=.276, .806 ; p=.006)$, severe mental distress $(\mathrm{OR}=.218$; $95 \% \mathrm{CI}=.143, .334 ; p<.000)$, HIV risk $(\mathrm{OR}=.509 ; 95 \% \mathrm{CI}=.356, .727 ; p<.000)$, and severe victimization $(\mathrm{OR}=.556 ; 95 \% \mathrm{CI}=.354, .873 ; p=.011)$ were associated with

Table 1. Selected characteristics of street-based female sex workers $(N=562)$.

\begin{tabular}{lcc}
\hline & $N$ & $\%$ \\
\hline $\begin{array}{l}\text { Demographics } \\
\text { Age (mean; SD) }\end{array}$ & 39.29 & \\
HIV-positive & 98 & $8.50)$ \\
Foster care history & 96 & 17.4 \\
& & \\
Risk factors & 308 & 54.8 \\
Homeless (past 90 days) & 443 & 78.8 \\
Severe mental distress & 501 & 89.1 \\
Substance dependence & 468 & 83.3 \\
Severe victimization & 282 & 50.2 \\
HIV risk & & \\
& 270 & 48.0 \\
Protective factors & 186 & 33.1 \\
Education $\geqslant 12$ years & 384 & 68.3 \\
Health care coverage & 55.20 & $(22.98)$ \\
Transportation access & & \\
Social support (mean; SD) & & \\
& & 33.3 \\
Resilience & 187 & \\
Personal mastery (66th percentile) & & \\
\hline
\end{tabular}

*Range: 19-95. 
Table 2. Bivariate logistic regression models predicting high levels of personal mastery $(N=562)$.

\begin{tabular}{lrrr}
\hline & $P$ & OR & $95 \%$ CI \\
\hline $\begin{array}{lrc}\text { Demographics } \\
\text { HIV-positive }\end{array}$ & .133 & 1.411 & $.901,2.212$ \\
Foster care history & .010 & .506 & $.301, .851$ \\
Risk factors & & & \\
Homeless (past 90 days) & .006 & .553 & $.361, .846$ \\
Severe mental distress & .000 & .218 & $.143, .334$ \\
Substance dependence & .006 & .472 & $.276, .806$ \\
Severe victimization & .011 & .556 & $.354, .873$ \\
HIV risk & .000 & .509 & $.356, .727$ \\
Protective factors & & & \\
Education $\geqslant 12$ years & & 1.797 & $.860,2.563$ \\
Health care coverage & .001 & 1.289 & $1.080,2.369$ \\
Transportation access & .177 & 1.599 & $1.021,1.040$ \\
Social support & .019 & 1.031 & \\
\hline
\end{tabular}

Table 3. Multivariate logistic regression models predicting high levels of personal mastery $(N=562)$.

\begin{tabular}{lccc}
\hline & $P$ & OR & $95 \%$ CI \\
\hline Risk factors & & & \\
Homeless & .126 & .722 & $.475,1.096$ \\
Severe mental distress & .000 & .268 & $.162, .445$ \\
Substance dependence & .429 & .781 & $.423,1.442$ \\
Severe victimization & .171 & .480 & $.845,2.594$ \\
HIV risk & .002 & & $.360, .802$ \\
& & & \\
Protective factors & .000 & 2.075 & $1.392,3.093$ \\
Education $\geqslant 12$ years & .163 & 1.379 & $.878,2.166$ \\
Transportation access & .000 & 1.025 & $1.015,1.035$ \\
Social support & & & \\
\hline
\end{tabular}

lower odds of having high personal mastery. Education $(\geqslant 12$ years; OR $=1.797 ; 95 \%$ $\mathrm{CI}=1.260,2.563 ; p=.001)$, transportation access $(\mathrm{OR}=1.599 ; 95 \% \mathrm{CI}=1.080,2.369$; $p=.019)$, and greater social support $(\mathrm{OR}=1.031 ; 95 \% \mathrm{CI}=1.021,1.040 ; p<.000)$ were associated with higher odds of high personal mastery.

Table 3 shows the results of the multivariate logistic regression model predicting a high level of personal mastery. Severe mental distress $(\mathrm{OR}=.268 ; 95 \% \mathrm{CI}=.162, .445$; $p<.000)$ and HIV transmission risk $(\mathrm{OR}=.537 ; 95 \% \mathrm{CI}=.360, .802 ; p=.002)$ remained associated with lower odds of having high personal mastery. The protective factors associated with high personal mastery were education $(\geqslant 12$ years; $\mathrm{OR}=2.075 ; 95 \%$ $\mathrm{CI}=1.392,3.093 ; p=.000)$ and greater social support $(\mathrm{OR}=1.025 ; 95 \% \mathrm{CI}=1.015$, $1.035 ; p<.000)$.

\section{Discussion and conclusion}

Findings from this study document the presence of resilience and associated protective factors among a sample of street-based African-American female sex workers. 
Syndemic risk factors experienced by this population include severe mental distress, substance dependence, HIV risk, and severe victimization. Previous examinations of the risk factors and vulnerabilities present among this sample have yielded new and important data that address HIV transmission and public health policy (Surratt \& Kurtz, 2011; Surratt et al., 2011). The present study furthers this work and demonstrates that in spite of multiple risk factors, many women express resilience which is related to lower levels of syndemic risk.

The overall pattern of results was that syndemic factors are negatively associated with high levels of personal mastery, while protective factors have a positive association. This is consistent with recent literature that has used a resilience framework to examine health disparities and outcomes (Moskowitz, 2010; Obrist et al., 2010; Pargament \& Cummings, 2010). To our knowledge, this is the only study to employ this perspective among this vulnerable population, and it advances the research among similar drug-using female sex worker populations in the USA

Our results identify specific targets for intervention to assist female sex workers in coping with syndemic risk factors and achieving better health outcomes. Protective factors, such as high school completion or GED equivalent, social support, and transportation access, could potentially facilitate the development of personal mastery and represent beneficial avenues for intervention. Because of the strong negative association between personal mastery and the variables severe mental distress and HIV transmission risk, approaches that enhance resilience are likely to have a beneficial effect on these syndemic risks as well.

To address these issues, community organizations and service providers should consider the value of indirect intervention approaches in the promotion of health behaviors and risk reduction. Outside the USA, community level empowerment interventions have been used successfully to address HIV risk and vulnerability among female sex workers (Kerrigan, Fonner, Stromdahl, \& Kennedy, 2013). However, community interventions and formal advocacy organizations that address health and social risks among female sex workers are lacking in Miami (Surratt et al., 2004). Female sex workers in Miami often have limited education and lack social or professional ties to the larger community, making it difficult to navigate the health and community resource systems (Surratt et al., 2004). Moreover, education has been identified by vulnerable female sex workers in Miami as an unmet need (Kurtz et al., 2005). Thus, prioritizing educational and training opportunities among this population with the objectives of decreasing economic reliance on sex work and reducing risk would appear to be a welcome and valuable tool for health promotion. This approach has been tested among female sex workers in Bangladesh and documents the association between increased educational opportunities and greater self-efficacy and condom use (Sarafian, 2012). Research suggests that increased educational attainment is also associated with lower HIV mortality rates (Simard, Fransua, Naishadham, \& Jemal, 2012).

The enhancement of social support would likely reduce syndemic risk among female sex workers. In our sample, social support scores tended to be lower than national norms among patients with chronic illnesses (Sherbourne \& Stewart, 1991). This is likely due to the prevalence of social conditions of unstable housing, substance use, poverty, violence, and social isolation among this population (Surratt \& Kurtz, 2011; Surratt et al., 2011). Findings from a risk reduction intervention study among street-based sex workers in Miami suggested that social support from peer counselors facilitated better engagement with and retention of the interventions (Surratt \& Inciardi, 2010). Thus, small efforts to address the lack of social support in any intervention are 
apt to have a positive impact. Further, research has demonstrated that a lack of social support has a negative effect on the initiation of HIV care after a recent diagnosis (McCoy et al., 2009). With the increasing adoption of HIV prevention initiatives such as Treatment as Prevention (Cohen et al., 2011), this could be an important domain to address in interventions for high risk populations, such as street-based female sex workers.

Transportation access had a considerable positive association with high levels of personal mastery in the bivariate logistic regression model. Research has shown that lack of transportation access can be a major barrier to service utilization and positive health outcomes (Hoerster et al., 2011; Sagrestano, Clay, Gooch, Finerman, \& Rapino, 2012), especially for African-Americans (Probst, Laditka, Wang, \& Johnson, 2007). Among marginalized female sex workers in Miami, lack of transportation access is a structural barrier that prevents women from obtaining needed health and social services and serves to confine them to resource-poor urban neighborhoods (Kurtz et al., 2005). Interventions that assist women in accessing reliable transportation could further reduce risk and make health services utilization, including HIV testing and treatment, more feasible.

These results should be viewed in the context of several limitations. The data were gathered through self-report, potentially leading to underreporting of socially undesirable behaviors or reporting biases. We are confident that the use of specially trained female staff mitigated such deficiencies, though caution is warranted in interpretation. Additionally, data presented here are cross-sectional which limits our ability to make causal inferences among the key variables. Finally, though the study contained a large sample, women who participated may not have been representative of all street-based sex workers in Miami, and the findings may not be generalizable to other populations.

Despite these limitations, this study provided substantial evidence of protective factors and resilience among street-based African-American female sex workers experiencing multiple syndemic risk factors. Responsive policies must be developed to address the lack of formal advocacy organizations that serve this marginalized population and provide assistance in accessing health care and social services. Though some organizations of this type exist elsewhere, the presence of such organizations in Miami is not apparent. Further, these analyses highlight the need for additional research. Comprehensive examinations of female sex workers and other vulnerable populations should investigate social and environmental protective factors that enhance individual capacity to cope with adverse conditions that lead to better health outcomes. Such a focus on resilience would produce valuable insight into the mitigation of syndemic risk factors, which would further inform intervention design and public health policy.

\section{Acknowledgments}

This research was supported by Grant Number R01DA013131 from the National Institute on Drug Abuse. The authors gratefully acknowledge Dr James A. Inciardi, Principal Investigator of this study through 2009 .

\section{References}

Baer, H.A., Singer, M., \& Susser, I. (1997). Medical anthropology and the world system: A critical perspective. Westport, CT: Bergin \& Garvey.

Bassuk, E.L., Buckner, J.C., Weinreb, L.F., Browne, A., Bassuk, S.S., \& Dawson, R. (1997). Homelessness in female headed families: Childhood and adult risk and protective factors. American Journal of Public Health, 87, 241-248. 
Bohlig, E.M., \& Dennis, M.L. (1996). Development of an abbreviated symptom checklist: Preliminary analysis of the HSCL-90 in a methadone-maintenance population. Research Triangle Park, NC: Research Triangle Institute.

Carlson, C.E., Chen, J., Chang, M., Batsuckh, A., Toivgoo, A., \& Riedel, M. (2012). Reducing intimate paying partner violence against women who exchange sex in Mongolia: Results from a randomized clinical trial. Journal of Interpersonal Violence, 27, 1911-1931.

Cohen, M., Chen, Y., McCauley, M., Gamble, T., Hosseinipour, M., \& Kumarasamy, N. (2011). Prevention of HIV-1 infection with early antiretroviral therapy. New England Journal of Medicine, 11, 469-505.

Dalla, R.L. (2001). Et tú brutè? A qualitative analysis of streetwalking prostitutes' interpersonal support networks. Journal of Family Issues, 22, 1066-1085.

DeNavas-Walt, C., Proctor, B.D., \& Smith, J.C. (2012). Income, poverty, and health insurance coverage in the United States: 2011 current population reports (pp. P60-P243). Washington, DC: US Census Bureau.

Dennis, M.L., Chan, Y.F., \& Funk, R. (2006). Development and validation of the GAIN short screener (GSS) for internalizing, externalizing, and substance use disorders and crime/violence problems among adolescents and adults. American Journal on Addictions, $15,80-91$.

Dennis, M.L., Titus, J.C., White, M.K., Unsicker, J.I., \& Hodgkins, D. (2002). Global appraisal of individual needs-initial (GAIN-I). Bloomington, IL: Chestnut Health Systems.

Ghimire, L., Smith, S.W.C., van Teijlingen, E.R., Dahal, R., \& Luitel, N.P. (2011). Reasons for non-use of condoms and self-efficacy among female sex workers: A qualitative study in Nepal. BMC Women's Health, 11, 1-8.

Guha, M., Baschieri, A., Bharat, S., Bhatnagar, T., Sane, S.S., \& Godbole, S.V. (2012). Risk reduction and perceived collective efficacy and community support among female sex workers in Tamil Nadu and Maharashtra, India: The importance of context. Journal of Epidemiology and Community Health, 66(Suppl. 2), ii55-ii61.

Herrick, A.L., Stall, R., Goldhammer, H., Egan, J.E., \& Mayer, K.H. (2013). Resilience as a research framework and as a cornerstone of prevention research for gay and bisexual men: Theory and evidence. AIDS and Behavior [Epub ahead of print]. doi:10.1007/s10461-012-0384-x

Hoerster, K.D., Mayer, J.A., Gabbard, S., Kronick, R.G., Roesch, S.C., \& Malcarne, V.L. (2011). Impact of individual-, environmental-, and policy-level factors on health care utilization among US farmworkers. American Journal of Public Health, 101, 685-692.

Inciardi, J.A., \& Surratt, H.L. (2001). Drug use, street crime and sex-trading among cocainedependent women: Implications for public health and criminal justice policy. Journal of Psychoactive Drugs, 33, 379-389.

Inciardi, J.A., Surratt, H.L., \& Kurtz, S.P. (2006). HIV, HBV, and HCV infections among drug-involved, inner-city, street sex workers in Miami, Florida. AIDS and Behavior, 10, $137-147$.

Institute of Behavioral Research (IBR). (2006). The TCU drug screen ii. Retrieved February 4, 2013, from http://www.ibr.tcu.edu/pubs/datacoll/Forms/ddscreen-95.pdf

Kerrigan, D.L., Fonner, V.A., Stromdahl, S., \& Kennedy, C.E. (2013). Community empowerment among female sex workers is an effective HIV prevention intervention: A systematic review of the peer-reviewed evidence from low- and middle-income countries. AIDS and Behavior, 17, 1926-1940.

Kurtz, S.P., Surratt, H.L., Inciardi, J.A., \& Kiley, M.C. (2004). Sex work and "Date" violence. Violence Against Women, 10, 357-385.

Kurtz, S.P., Surratt, H.L., Kiley, M.C., \& Inciardi, J.A. (2005). Barriers to health and social services for street-based sex workers. Journal of Health Care for the Poor and Underserved, $16,345-361$.

McCoy, S.I., Strauss, R.P., MacDonald, P.D.M., Leone, P.A., Eron, J.J., \& Miller, W.C. (2009). Social support and delays seeking care after HIV diagnosis, North Carolina, 2000-2006. AIDS Care, 21, 1148-1156.

Millstein, B. (2002). Introduction to the syndemics prevention network. Retrieved February 12, 2011, from http://www.cdc.gov/syndemics/pdfs/network-intro.pdf

Moskowitz, J.T. (2010). Positive affect at the onset of chronic illness: Planting the seeds of resilience. In J.W. Reich, A.J. Zautra, \& J.S. Hall (Eds.), Handbook of adult resilience (pp. 465-483). New York, NY: Guildford Press. 
Obrist, B., Pfeiffer, C., \& Henley, R. (2010). Multi-layered social resilience: A new approach in mitigation research. Progress in Development Studies, 10, 283-293.

Pargament, K.I., \& Cummings, J. (2010). Anchored by faith: Religion as a resilience factor. In J.W. Reich, A.J. Zautra, \& J.S. Hall (Eds.), Handbook of adult resilience (pp. 193-210). New York, NY: Guilford Press.

Parrish, D.D., \& Kent, C.K. (2008). Access to care issues for African American communities: Implications for STD disparities. Sexually Transmitted Diseases, 35, S19-S22.

Pearlin, L.I., Menaghan, E.G., Lieberman, M.A., \& Mullan, J.T. (1981). The stress process. Journal of Health and Social Behavior, 22, 337-356.

Pearlin, L.I., \& Schooler, C. (1978). The structure of coping. Journal of Health and Social Behavior, $19,2-21$.

Prejean, J., Song, R., Hernandez, A., Ziebell, R., Green, T., \& Walker, F. (2011). Estimated HIV incidence in the United States, 2006-2009. PLOS ONE, 6, e17502. doi:10.1371/journal. pone. 0017502

Probst, J.C., Laditka, S.B., Wang, J.-Y., \& Johnson, A.O. (2007). Effects of residence and race on burden of travel for care: Cross sectional analysis of the 2001 US National Household Travel Survey. BMC Health Services Research, 7(40), 1-13.

Roepke, S.K., \& Grant, I. (2011). Toward a more complete understanding of the effects of personal mastery on cardiometabolic health. Health Psychology, 30, 615-632.

Romero-Daza, N., Weeks, M., \& Singer, M. (2003). "Nobody gives a damn if Ilive or die". Experiences of violence among drug-using sex workers in Hartford, Connecticut. Medical Anthropology, 22, 233-259.

Romero-Daza, N., Weeks, M., \& Singer, M. (2005). Conceptualizing the impact of indirect violence on HIV risk among women involved in street-level prostitution. Aggression and Violent Behavior, 10, 153-170.

Sagrestano, L., Clay, J., Gooch, J., Finerman, R., \& Rapino, M. (2012). Examining transportation as a barrier to service utilization for PLWHA. Paper presented at the American Public Health Association, San Francisco, CA.

Sarafian, I. (2012). Process assessment of a peer education programme for HIV prevention among sex workers in Dhaka, Bangladesh: A social support framework. Social Science and Medicine, 75, 668-675.

Schnittker, J., Massoglia, M., \& Uggen, C. (2011). Incarceration and the health of the Afican American community. Du Bois Review: Social Science Research on Race, 8, 133-141.

Seeman, M. (1991). Alienation and anomie. In J.P. Robinson, P.R. Shaver, \& L.S. Wrightsman (Eds.), Measures of personality and social spychological attitudes (Vol. 1, pp. 292-372). San Diego, CA: Academic Press.

Shannon, K., \& Csete, J. (2010). Violence, condom negotiation, and HIV/STI risk among sex workers. Journal of the American Medical Association, 304, 573-574.

Shannon, K., Kerr, T., Allinott, S., Chettiar, J., Shoveller, J., \& Tyndall, M.W. (2008). Social and structural violence and power relations in mitigating HIV risk of drug-using women in survival sex work. Social Science and Medicine, 66, 911-921.

Sherbourne, C.D., \& Stewart, A.L. (1991). The MOS social support survey. Social Science and Medicine, 32, 705-714.

Simard, E.P., Fransua, M., Naishadham, D., \& Jemal, A. (2012). The influence of sex, race/ ethnicity, and educational attainment on human immunodeficiency virus death rates among adults, 1993-2007. Archives of Internal Medicine, 172, 1591-1598.

Singer, M. (2009). Introduction to syndemics: A critical systems approach to public and community health. San Francisco, CA: Jossey-Bass.

Singer, M., \& Snipes, C. (1992). Generations of suffering: Experiences of a treatment program for substance abuse during pregnancy. Journal of Health Car for the Poor and Underserved, $3,222-239$.

Spittal, P.M., Bruneau, J., Craib, K.J.P., Miller, C., Lamothe, F., \& Weber, A.E. (2003). Surviving the sex trade: A comparison of HIV risk behaviors among street-involved women in two Canadian cities who inject drugs. AIDS Care, 15, 187-195.

Surratt, H.L., \& Inciardi, J.A. (2004). HIV risk, seropositivity and predictors of infection among homeless and non-homeless women sex workers in Miami, Florida, USA. AIDS Care, 16, 594-604. 
Surratt, H.L., \& Inciardi, J.A. (2010). An effective HIV risk reduction reduction protocol for drug-using women sex workers. Prevention and Intervention in the Community, 38, 118-131.

Surratt, H.L., Inciardi, J.A., Kurtz, S.P., \& Kiley, M.C. (2004). Sex work and drug use in a subculture of violence. Crime \& Delinquency, 50, 43-59.

Surratt, H.L., \& Kurtz, S.P. (2011). Foster care history and HIV infection among drug-using African American female sex workers. AIDS and Behavior, 16, 982-989.

Surratt, H.L., Kurtz, S.P., Chen, M., \& Mooss, A. (2011). HIV risk among female sex workers in Miami: The impact of violent victimization and untreated mental illness. AIDS Care, 24, $553-561$.

Surratt, H.L., Kurtz, S.P., Weaver, J.C., \& Inciardi, J.A. (2005). The connections of mental health problems, violent life experiences, and the social milieu of the "Stroll" with the HIV risk behaviors of female street sex workers. Journal of Psychology and Human Sexuality, $17,23-44$

Susser, E., Moore, R.A., \& Link, B. (1993). Risk factors for homelessness. American Journal of Epidemiology, 15, 546-556.

Titus, J.C., Dennis, M.L., White, W.L., Scott, C.K., \& Funk, R.R. (2003). Gender differences in victimization severity and outcomes among adolescents treated for substance abuse. Child Maltreatment, 8, 19-35.

Ungar, M. (2008). Resilience across cultures. British Journal of Social Work, 38, 218-235.

Waters, J.K., \& Biernacki, P. (1989). Targeted sampling: Options for the study of hidden populations. Social Problems, 36, 416-430.

Weiner, A. (1996). Understanding the social needs of streetwalking prostitutes. Social Work, 41, 97-105.

Younger, J.B. (1991). A theory of mastery. Advances in Nursing Science, 14, 76-89. 